Nevşehir Bilim ve Teknoloji Dergisi TARGíd Özel Sayı 325-331 2016

DOI: 10.17100/nevbiltek.211022

URL: http://dx.doi.org/10.17100/nevbiltek.211022

\title{
Ada Çayı (Salvia virgata Jacg.) Tohumlarının Bazı Fiziksel Özelliklerinin
}

\section{Belirlenmesi}

\author{
Mustafa Bayram $^{1 *}$, Melih Yılar ${ }^{2}$, Engin Özgöz ${ }^{1}$, İzzet Kadığlu ${ }^{3}$ \\ ${ }^{1}$ Gaziosmanpaşa Üniversitesi, Ziraat Fakültesi Biyosistem Mühendisliği Bölümü-Tokat \\ ${ }^{2}$ Ahi Evran Üniversitesi, Ziraat Fakültesi, Bitki Koruma Bölümü-Kırşehir \\ ${ }^{3}$ Gaziosmanpaşa Üniversitesi, Ziraat Fakültesi Bitki Koruma Bölümü-Tokat
}

Öz

Ada çayı (Salvia virgata Jacg.); yılancık ismi ile bilinen, halk arasında yara iyileştirici olarak kullanılan ve ülkemizde doğal olarak yayılış gösteren ada çayı türlerinden biridir. Bu çalışma ile Tokat ili Artova ilçesi’nden toplanan Salvia virgata Jacq. tohumlarının bazı fiziksel özelliklerinin belirlenmesi amaçlanmıştır. Çalışma kapsamında tohumların nem içerikleri, ortalama geometrik çap, birim ağırlık, küresellik, bin dane ağırlığı, yığın hacim ağıllı̆̆, yüzey alanı ve doğal yığılma açısı değerleri belirlenmiştir. Buna göre kuru bazdaki nem içeriği ortalama \% 6.41, bin dane ağırlığı $1.58 \mathrm{~g}$, dane ağırlığı 0.0034 g'dır. Ortalama tohum uzunluğu, genişliği ve kalınlığı sırasıyla 2.39, 1.61, 1.31 mm olarak belirlenmiştir. Tohumların ortalama geometrik çapı, küreselliği ve yüzey alanı 1.71 mm, \%72.03 ve $10.97 \mathrm{~mm}^{2}$ olarak belirlenmiştir. Bununla birlikte ortalama hacim ağıllığı $352.33 \mathrm{~kg} \mathrm{~m}^{-3}$ ve ortalama doğal yığılma açısı $9.72^{\circ}$ olarak saptanmıştır. Ayrıca çalışmada elde edilen sonuçlara göre tohumlar için makine ve ekipmanların tasarlanmasında farklı nem içeriklerine sahip tohum fiziksel ve mekanik özelliklerinin de dikkate alınmasının yararlı olacağı sonucuna varılmıştır.

Anahtar kelimeler: Adaçayı, tohum, fiziksel özellikler, salvia virgata Jacg.

\section{Determined of Some Physical Properties of Sage seed (Salvia virgata Jacq.)}

\section{Abstract}

Sage (Salvia virgata Jacq.); known by the name of erysipelas, which is used as wound healing between the people and our country is a plant which spreads naturally. In this study, the district of Tokat province Artova collected seeds of Salvia virgata Jacq. aimed to determine some physical properties. Working under the seed moisture content, mean geometric diameter, unit weight, sphericity, thousand grain weight stack, weight, surface areas, and angle of repose values were determined. Accordingly, the moisture content of $6.41 \%$ on a dry basis, thousand grain weight $1.58 \mathrm{~g}$, grain weight of $0.0034 \mathrm{~g}$, the average seed length, width and thickness, respectively, 2.39, 1.61 and $1.31 \mathrm{~mm}$ as determined. The seeds of geometric mean diameter, sphericity, surface area $1.71 \mathrm{~mm}$, was determined as $72.03 \%$ and $10.97 \mathrm{~mm}^{2}$. However, the mean bulk density of $352.33 \mathrm{~kg} \mathrm{~m}^{-3}$ and the average angle of repose was found to be $9.72^{\circ}$. Furthermore studies based on the results obtained with different moisture content for the develop of machinery and equipment for seed grain was concluded to be useful to take into account the physical and mechanical properties.

Keywords: Sage, seed, phsical properties, Salvia virgata Jacg.

\footnotetext{
*e-mail: mustafa.bayram@gop.edu.tr
} 


\section{Giriş}

Tohumların fiziksel özelliklerinin bilinmesi tohumların taşınması, depolanması ve işlenmesi için gerekli ekipmanların tasarlanmasında ve geliştirilmesinde oldukça önemlidir [1]. Özellikle gıda, tedavi ve insan için önem arz eden bitkilerin tohum özelliklerinin bilinmesi büyük öneme sahiptir. Dünyada geniş bir alana yayılmış Lamiaceae familyasında yer alan Salvia tür sayısı ülkemizde son yapılan çalışmalara göre 95'e ulaşmış olup endemizm oranı \% 51'dir [2,3,4]. Salvia cinsine mensup Salvia virgata Jacq. türü çok yıllık, 20-160 cm boylanabilen, çoğunlukla çalılıklar, ormanlar, çayırlar, boş tarlalar, kireç taşlı ve volkanik kayalıklar, yol kenarları gibi çok değişik habitatları tercih eden bir bitkidir. Deniz seviyesinden 2300 m’ye kadar yayılış gösterir. Çiçeklenme zamanı Mayıs-Eylül ayları arasındadır. Kırım, Balkanlar, İtalya, Kafkaslar, Kuzey Irak, İran, Afganistan ve Orta Asya'da yayılış gösteren S. virgata Jacq. Türkiye'nin her yerinde ve adalarda yayılış göstermektedir [5]. Salvia virgata Jacq.'’n yayılışı ve önemi Tokat yöresinde yapılan bir çalışma ile ayrıca ortaya konmuştur [6].

S. virgata Jacq. tıp uygulamalarında yararlanılan önemli ve yüksek değerli bir bitki olması yanında halk arasında yara iyileştirici, cilt hastalıklarına, kan kanserine karşı [3 ve 7] kullanılıyor olması bitkinin önemini artırmaktadır. Ülkemizde yaygın olarak bulunan bu bitkinin tohumlarının fiziksel özelliklerine ilişkin yapılmış herhangi bir bilimsel literatüre rastlanmamıştır. Salvia türleri üzerinde sadece [8] ve [9] tarafından Salvia hispanica L. tohumlarının fiziksel özelliklerinin belirlenmesine yönelik çalışmalar mevcuttur. Ayrıca Triticum [10], Vicia [11], Sesamum [12], Cotton [13], Foeniculum [14], Parkia [15] ve Polygonum [16 ve17] gibi cinslerin takson tohumlarının fiziksel özellikleri incelenmiştir.

Bu çalışmada, Tokat İli Artova ilçesinde doğal olarak yayılış gösteren S.virgata Jacq. tohumlarının boyut, şekil, hacim ağırlığı, küresellik, yüzey alanı, doğal yığılma açısı ile nem içeriği gibi bazı fiziksel özellikleri belirlenmiştir.

\section{Materyal ve Metod}

S.virgata Jacq. (Şekil 1) Tokat İli Artova İlçesi’nden 2012-2013 yıllarındaki vejetasyon döneminde toplamış ve bitkiler gölgede kurutulmuştur. Daha sonra tohumlar ayıklanarak oda koşullarında muhafaza edilmiştir. Tohumların fiziksel özellikleri belirlenmeden tohumlar $105{ }^{\circ} \mathrm{C}$ 'de etüvde 24 saat bekletilerek nem içerikleri belirlenmiştir [28].

Belirlenen nem içeriğinde rastgele seçilen 100 S.virgata Jacq. tohumunun uzunluk, genişlik, kalınlık ve ağırlıkları ölçülmüştür. Uzunluk, kalınlık ve genişlik ölçümleri $0.001 \mathrm{~mm}$ hassasiyetli dijital kumpas kullanılarak gerçekleştirilmiştir. Ağırlıkları ise $0.001 \mathrm{~g}$ hassasiyetli elektronik hassas terazide ölçülerek tohumların birim ağırlıkları belirlenmiştir.

Bin dane ağırlığı yığın içerisinden rastgele 10 tane 100 adet tohumtar tıldıktan sonra ortalaması 10 ile çarpılarak belirlenmiştir [14]. Hacim ağırlığg bir tohum örneği kütlesinin toplam hacmine oranıdır. Hacim ağırlığı hektolitre kabı kullanılarak kg mº olarak Eşitlik-1’e gore belirlenmiştir [21ve 22].

$$
P b=\left[\frac{m b}{V b}\right]
$$


Doğal yığılma açısı tohum yığın halinde durduğunda materyalin yatayla yapmış olduğu açıdır. Bu yüksekliği $500 \mathrm{~mm}$ ve çapı $300 \mathrm{~mm}$ olan alt ve üst kısımları açık bir silindir kullanılarak belirlenmiştir. Silindir dairesel bir plakanın merkezine yerleştirildikten sonra tohumla doldurulmuş ve dairesel plaka üzerinde bir koni oluşuncaya kadar silindir yavaşça yükseltilmiştir. Yığılma açısı oluşan koninin yüksekliği ve çapı ölçülerek hesaplanmıştır [23].

Tohumların boyut özellikleri kullanılarak geometrik ortalama çap Eşitlik-2 ve küresellikleri ise Eşitlik-3'e [24] göre hesaplanmıştır.

$$
D_{g}=(L W T)^{1 / 3} \quad \text { (2) } \quad \Phi=\left[\frac{L W T^{1 / 3}}{L}\right] \times 100
$$

Yüzey alanı tohumların geometrik ortalama çapları kullanılarak Eşitlik-4'e göre hesaplanmıştır $[12,18,25]$.

$$
S=\pi D_{g}^{2}
$$

Çalışmada son olarak parametrelere ait tanımlayıcı istatistik (ortalama, maksimum, minimum ve standart sapma) ve korelasyon analizi SPSS 13 [19] bilgisayar programı kullanılarak yapılmıştır.

\begin{tabular}{|cllll|}
\hline \multicolumn{3}{|c|}{ Semboller ve kısaltmalar } & \\
$D_{g}$ & geometrik ortalama çap, mm & $T$ & kalınlık, mm \\
$L$ & uzunluk, mm & $W$ & genişlik, mm \\
$M$ & birim ağırlık, $\mathrm{g}$ & $\rho_{b}$ & hacim ağırlı̆ $\mathrm{g}_{1}, \mathrm{~kg} \mathrm{~m}^{-3}$ \\
$S$ & yüzey alanı, $\mathrm{cm}^{2}$ & $\Phi$ & küresellik, \% \\
$\Theta$ & yı̆̆ılma açısı, derece & & \\
\hline
\end{tabular}

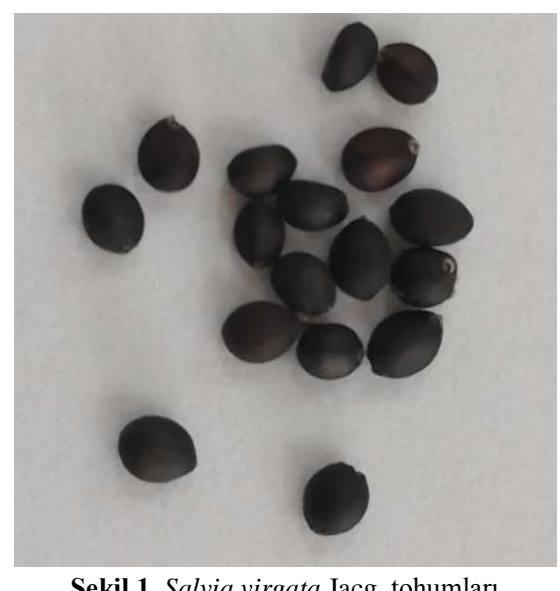

Sekil 1. Salvia virgata Jacg. tohumları

\section{Bulgular}

Bu çalışma kapsamında Tokat İli Artova ilçesinden toplanan S. virgata Jacq. tohumlarının bazı fiziksel özellikleri incelenmiş olup sonuçlar Tablo1'de özetlenmiştir. Buna göre tohumlarının ortalama nem içeriği \% 6.41 iken S. virgata Jacq. tohumlarının boyutsal özelliklerinden uzunluk, genişlik ve kalınlıkları bu nem içeriğinde maksimum 2.88, 2.07 ve 1.59 mm olarak belirlenmiştir. Tane ağırlığının en fazla 0.0049 g olduğu tohumların hacim ağırlı̆ıının ise maksimum $356.57 \mathrm{kgm}^{-3}$ olduğu görülmüștür. 
Çalışmada taşıma, paketleme ve özellikle ürün işleme makinalarının tasarımı ile geliştirilmesinde göz önünde bulundurulan geometrik ortalama çap, yüzey alanı, yığılma açısı ve küresellik katsayıları hesaplanarak maksimum $1.71 \mathrm{~mm}, 10.97 \mathrm{~mm}^{2}, 9.72^{0}$ ve $\% 72.03$ olarak bulunmuştur.

Tablo 1. S. virgata Jacg. tohumlarının bazı fiziksel özellikleri

\begin{tabular}{|c|c|c|c|c|c|c|}
\hline Fiziksel özellikler & Birim & Gözlem sayısı & Minimum & Maksimum & Ortalama & Standart sapma \\
\hline Uzunluk & $\mathrm{mm}$ & 100 & 1.98 & 2.88 & 2.39 & 0.20 \\
\hline Genişlik & $\mathrm{mm}$ & 100 & 1.26 & 2.07 & 1.61 & 0.14 \\
\hline Kalınlık & $\mathrm{mm}$ & 100 & 1.18 & 1.59 & 1.31 & 0.09 \\
\hline Geometrik ortalama çap & $\mathrm{mm}$ & 100 & 1.48 & 1.96 & 1.71 & 0.10 \\
\hline Yüzey alanı & $\mathrm{mm}^{2}$ & 100 & 8.37 & 14.00 & 10.97 & 1.20 \\
\hline Yığılma açısı & 0 & 3 & 5.11 & 13.35 & 9.72 & 4.21 \\
\hline Küresellik & $\%$ & 100 & 62.74 & 82.11 & 72.03 & 3.72 \\
\hline
\end{tabular}

Çalışmada tohumlara ilişkin bazı özellikler arasında yapılan pearson korelasyon analizine göre tohumların uzunluk ve genişlikleri ile geometrik ortalama çap arasında istatistiksel olarak $\mathrm{p}<0.01$ önem düzeyinde pozitif yönde yüksek korelasyon görülmüştür (Tablo 2).

Tablo 2. S. virgata Jacg. tohumlarının bazı fiziksel özelliklerine ait pearson korelasyon analizi sonuçları

\begin{tabular}{|c|c|c|c|c|c|c|c|c|c|}
\hline & Uzunluk & Genișlik & Kalınlık & $\begin{array}{l}\text { Geometrik } \\
\text { Ort. çap }\end{array}$ & Küresellik & $\begin{array}{l}\text { Yüzey } \\
\text { alanı }\end{array}$ & $\begin{array}{l}\text { Tane } \\
\text { ağırlık }\end{array}$ & $\begin{array}{l}\text { Yığılma } \\
\text { acısı }\end{array}$ & $\begin{array}{l}\text { Hacim } \\
\text { ağırlığı }\end{array}$ \\
\hline Uzunluk & 1.00 & & & & & & & & \\
\hline Kalınlık & $0.26^{* *}$ & $0.30^{* *}$ & 1.00 & & & & & & \\
\hline Geometrik ort. çap & $0.80^{* *}$ & $0.81^{* *}$ & $0.63^{* *}$ & 1.00 & & & & & \\
\hline Dane ağırlık & 0.09 & 0.03 & 0.06 & 0.08 & -0.06 & 0.07 & 1.00 & & \\
\hline Yığılma açısı & 0.30 & 0.64 & 0.07 & 0.37 & -0.22 & 0.36 & -0.72 & 1.00 & \\
\hline Hacim ă̆ırlığı & 0.97 & 0.80 & $1.00^{*}$ & 0.94 & -0.98 & 0.95 & -0.72 & 0.05 & 1.00 \\
\hline
\end{tabular}

Tohumların kalınlıkları ile hacim ağırlıkları arasında p<0.05 önem düzeyinde yüksek korelasyon görülürken, yüzey alanın uzunluk, kalınlık, genişlik ve geometrik ortalama çap ile arasında da $p<0.01$ önem düzeyinde yüksek korelasyon görülmüştür. Ayrıca tohumların uzunluk ve küreselliği arasında önemli bir negatif bir korelasyon ( $\mathrm{p}<0.01)$ görülmüştür (Tablo 2).

\section{Tartışma ve Sonuç}

Salvia virgata Jacq. tohumlarının bu çalışmada belirlenen bazı fiziksel özellikleri Tablo1'de verilmiştir. Tohumların depolanması ve muhafazasında en hayati özellik olan nem içeriği [15] çalışmamızda (kuru baza göre) \% 6.25 ile \%6.58 arasında değişmiştir. Genel olarak tohumların ortalama nem içeriği ise \%6.41 olarak bulunmuştur. Yapılan bir çalışmada oda koşullarında S. hispanica L. tohumlarının kuru baza göre nem içeriği ortalama \% 7 olduğu bildirilmiştir [8]. Belirlenen bu nem içeriği tohumların canlılığını koruyabildiği ve depolanması durumunda hızlı çimlenemeyeceği nem içeriği olarak tayin edilmiştir. Tohumların belirlenen fiziksel özellikleri tohumların muhafaza edilmesi gereken kabındeponun şeklinin, yapısının ve koşulların belirlenmesi için oldukça önemlidir [26]. 
Tohumların ortalama uzunluk, genişlik ve kalınlıkları sırasıyla $2.38( \pm 0.20), 1.61( \pm 0.14)$ ve 1.31 ( \pm 0.09$)$ mm’dir (Tablo1). S. hispanica siyah ve beyaz tohumlarının uzunluk, genişlik ve kalınlık değerleri sırasıyla 2.11-2.15; 1.32-1.40; 0.81-0.83 olarak belirlenmiştir [8]. Çalışmada elde edilen boyut özelliklerinin kadife çiçeği tohumları [27], madımak tohumları [16] ve rezene tohumlarından [14] daha küçük olduğu görülmüştür. Tohumların belirlenen bu boyutları tohumların makine ile yapılabilecek hasat, işleme ve ayıklama gibi pek çok işlemde kullanılmasında değerlendirilebilecek önemli parametrelerdir. Çalışmada hesaplanan geometrik ortalama çap 1.48 mm’den 1.96 mm’ye kadar değişimektedir. S. hispanica tohumlarının geometrik ortalama çapı 1.28-1.36 mm aralığında olduğu bildirilmiştir [8 ve 9]. Elde edilen geometrik ortalama çap teorik olarak tohumların hacimlerinin ve küreselliklerinin belirlenmesinde kullanılabilmektedir [16].

Tohumların ortalama küreselliği ve yı̆̆ılma açısı sırasıyla \% $72.03( \pm 3.72)$ ve $9.72^{0}( \pm 4.21)$ olarak belirlenirken tohumların birim ağırlığı ortalama (100 tohum) $0,034( \pm 0.0008)$ g olarak belirlenmiştir. Tohumların bin dane ağırlıkları ise ortalama $1.85 \mathrm{~g}$ olarak belirlenmiştir (Tablo 1).Tohumların hacim ağırlıkları ise en düşük $349.63 \mathrm{kgm}^{-3}$ en yüksek $356.57 \mathrm{kgm}^{-3}$ ve ortalama 352.33 $( \pm 3.72) \mathrm{kgm}^{-3}$ olduğu belirlenmiştir. Adaçayı tohumlarının hacim ağırlıklarının rezene tohumu[14] hacim ağırlığına benzer olduğu görülmüştür.Tohumların hacim ağırlıkları aynı zamanda tohumların depolanma kapasitelerini ortaya koyduğu için oldukça önemli bir kriterdir [15]. Ada çayı tohumlarının yüzey alanları $8.37 \mathrm{~mm}^{2}$ ile $14.00 \mathrm{~mm}^{2}$ arasında değişirken ortalama yüzey alanı $10.97 \mathrm{~mm}^{2}$ olarak bulunmuştur (Tablo 1).

Yapılan çalışmada S.virgata Jacq. tohumlarının önemli bazı fiziksel özellikleri belirlenmiş ve elde edilen sonuçlara göre tohumların boyutlarının karşılaştırılan bazı bitki tohumlarından oldukça küçük olduğu görülmüştür. Ülkemizde sadece kırsal kesimde tıbbi açıdan kullanımı yaygın olan S.virgata Jacq. tohumlarının temin edilmesindeki zorluklar ticari olarak pazarlanmasını ve üretim aşamasına geçilmesini güçleştirmektedir.

Tohumlara ilişkin ölçülen pek çok fiziksel özellik arasında önemli korelasyon görülmüştür. Bunlar arasında özellikle en yüksek korelasyon katsayısı tohumların yüzey alanı ile geometrik ortalama çapı arasında (0.99) olmuştur. Elde edilen bu sonuçlara göre bazı fiziksel özellikler arasındaki korelasyon katsayısı kullanılarak değişkenlerin farklı şekilde eşitliklerle yardımıyla ifade edilebileceği görülmüştür [20] (Tablo 2). Bu durumfarklı koşullar altında da bu özelliklerin incelenmesinin gerekli olduğunu ortaya koymuştur. Elde edilen sonuçlar tohumların taşınması, depolanması ve işlenmesi için gerekli ekipmaların geliştirilmesinde yeterli olmasına rağmen farklı nem koşullarında da bu özelliklere ek olarak tohumların mekanik özelliklerinin incelenmesinin faydalı olacağı düşünülmektedir. Elde edilen sonuçların bu bitkinin kimyasal ve biyolojik özelliklerininde belirlenmesinde rehberlik edecek nitelikte olduğu görülmüştür.

\section{Kaynaklar}

[1] Zewdu A.D. "Moisture-dependent physical properties of Ajwain (Trachyspermum ammi L.) Seeds”. Philipp Agric Scientist, 94 (3), 278-284, 2011.

[2] Davis P.H.“Flora of Turkey and the East Aegean Island”, Vol. 7, Edinburgh University Press, Edinburg, 1982.

[3] Poyraz İ.E., Koca F.,“Eskişehir'de yetişen bazı tıbbi Salvia türleri üzerinde morfolojik araştırmalar”,Anadolu Üniversitesi Bilim ve Teknoloji Dergisi,7(2), 443-450, 2006. 
[4] Celep F., Doğan M., Duran, A.A.,"New record for the flora of Turkey: Salvia viscosa Jacq.(Labiatae)”. Türk J. Bot.,32, 57-60, 2009.

[5] Karabacak E. “Türkiye'nin Avrupa-Sibirya Fitocoğrafik Bölgesindeki Salvia L. (Lamiaceae) Cinsinin Revizyonu”, Çanakkale Onsekiz Mart Üniversitesi. Fen Bilimleri Enstitüsü, Doktora Tezi, 2009.

[6] Yılar M., “Tokat Ve Çevresinde Yaygın Olarak Görülen Salvia Türlerinin Antifungal Ve Biyoherbisidal Aktivitelerinin Belirlenmesi”,Gazisomanpaşa Üniversitesi, Fen Bilimleri Enstitüsü, Doktora Tezi, Tokat, 2014.

[7] Sari A., Kursat M., Civelek, S., "Determination of MDA levels in the plant (Some Salvia L. Taxa growing in Turkey). Drug Metabolism \& Toxicology 3, (3) 1-2, 2012.

[8] Ixtaina V.Y., Nolasco S.M., Tomas M.C., "Physical properties of chia (Salvia hispanica L.) seeds”,Industrial Crops and Product,28, 286-293, 2008.

[9] Porras-Loaiza P., Jimenez-Munguıa M.T., Sosa-Morales M.E., Palou E., Lopez-Malo A., "Physical, properties, chemical characterization and fatty acid composition of Mexican chia (Salvia hispanica L.) seeds”,International Journal of Food Science \& Technology, 49, 571$577,2014$.

[10] Tabatabeefar A.,"Moisture-dependent physical properties of wheat. International Agrophysics, 17: 207-211, 2003.

[11] Yalçın İ., Özarslan C., “Physical properties of Vetch seed”, Biosystems Engineering. 88 (4) 507512, 2004.

[12] Tunde-Akintunde T.Y., Akintunde B.O., “Some physical properties of sesame seed”,Biosystems Engineering,88, 127-129, 2004.

[13] Manimehalai N., Viswanathan R.,"Physical properties of fuzzy cottonseeds” Biosystems Engineering, 95, (2) 207-217, 2006.

[14] Ahmadi H., Mollazade K., Khorshidi J., Mohtasebi S.S. Rajabipour A., "Some physical and mechanical properties of fennel seed (Foeniculum vulgare)”, Journalof Agricultural Sciene, 1, (1) 66-75, 2009.

[15] Abdullah M.H.R.O., Ch’ng P.E., Lim T.H., “Some physical properties of parkia speciosa seeds”, International Conference on Food Engineering and Biotechnology, 9, 43-47, 2011.

[16] Önen H., Altuntaş E., Özgöz E., Bayram M., Özcan S., “Moisture effect on physical properties of Knotweed (Polygonum cognatum Meissn.) seeds”,Journal of Agricultural Faculty of Gaziosmanpasa University (JAFAG).31 (2), 15-24, 2014.

[17] Kılıç Ö, "A Morphological Study on Five Polygonum L.(Polygonaceae) Species from Turkey" Düzce Üniversitesi Bilim ve Teknoloji Dergisi 2. (2) 475-486, 2014.

[18] Sacilik K., Ozturk R., Keskin R., “Some physical properties of hemp grain”,Biosystems Engineering, 86, 213-215, 2003.

[19] SPSS 2000. “SPSS for Windows”. Student Version. Release 10.0.9 SPSS Inc IL USA.

[20] Kaliniewicz Z., Jadwisieńczak K., Zalewska K., Sosińska E., "Variability and correlation of the selected physical properties of pumpkin seed (Cucurbita pepo L.)”, Agricultural Engineering, 18, 2014. 
[21] Deshpande S.D., Bal S., Ojha T.P.,"Physical properties of soybean grains”,Journal of Agricultural Engineering Research, 56, 89-92, 1993.

[22] Suthar S.H., Das S.K.,"Some physical properties of karingda [Citrus lanatus (thumb) mansf] grains” Journal of Agricultural Engineering Research, 65, 15-22, 1996.

[23] Kaleemullah S., Gunasekar J.J.,"Moisture-dependent physical properties of arecanut trues” Biosystems Engineering,. 82, 331-338, 2002.

[24] Mohsenin N.N., "Physical properties of plant and animal materials"Gordon and Breach Science Publishers. p 734, New York, 1970.

[25] Olajide J.D., Ade-Omowaye B.I.O., "Some physical properties of locust bean seed”Journal of Agricultural Engineering Research, 74, 213-215, 1999.

[26] Davies R.M.,“Some physical properties of Arigo seeds”Int. Agrophys, 24, 89-92, 2010.

[27] Abalone R., Cassinera A., GastonA., Lara M.A., "Some physical properties of Amaranth Seeds, Biosystems Engineering, 89 (1),109-117, 2004.

[28] Ozarslan C., "Physical properties of cotton seed”, Bio Engineering, 83(2), 169-174, 2002. 